\title{
START-ED: A MODEL FOR COMMERCIAL CLINICAL LEGAL
}

\section{EDUCATION}

David Collins*, Eric Klotz**, Ben Robinson***, City, University of London, UK

\section{Abstract}

This article outlines a pro bono student law clinic project focusing on providing legal assistance to startup businesses in central London. Serving more than 500 clients over this period, the clinic adapted to a number of problems by modifying its format with an emphasis on flexibility and informality. Additionally, the clinic implemented a survey in order to streamline the delivery of its advice. Data was collected from over 460 startups over a two year period between 2013 and 2015 regarding the nature of their business as well as the type of legal challenges they faced. The study revealed the primary need for basic legal advice on a few select matters including most notably company structure. In addition to collecting data on startups in London, the clinic project is presented as both a model for successful clinical education and example of how the university sector can act to boost innovation and the entrepreneurial economy.

\section{INTRODUCTION}

Clinical legal education is now widely viewed as one of the most important contributors to law students' employability, yet many law schools in the UK and abroad offer very limited exposure to such opportunities, particularly those which engage with commercial law. This is problematic because students struggle to satisfy

\footnotetext{
* David Collins is Professor of International Economic Law; JD, BCL, PhD; Solicitor (England and Wales), Admitted to the Bars of Ontario and New York

${ }^{* *}$ Eric Klotz is a Visiting Lecturer; PhD, GDL; Solicitor (England and Wales)

${ }^{* * *}$ Ben Robinson is the Community Volunteering Officer, GE LLB
} 
law firms' requirement of "commercial awareness" among their recruits during their law studies. This dilemma within legal education must be viewed in the context of the often under-appreciated need for low-cost commercial legal advice for many small businesses, especially those which have untested ideas or unproven track records of success, such as startups. Just as law students require exposure to genuine commercial settings to apply their knowledge with a view to developing skills which will advance their careers, startups are needful of assistance from those with legal expertise who are willing to share it for free. Operating legal clinics can be resource intensive and careful planning must be undertaken to ensure that the experience has maximum benefit for students and for the clinic's clients.

The role of lawyers to the success of startups is well recognized by commentators ${ }^{1}$ much as it is understood that failure to appreciate the importance of legal issues and plan accordingly from an early stage can be fatal to a startup. ${ }^{2}$ The need for governments to reduce startup costs in order to stimulate economic growth through self-employment and innovation have also been identified. ${ }^{3}$ Perhaps nowhere is this more evident than London, which is a hub of commercial activity in a wide range of sectors and which is host to a vibrant startup ecosystem, just as it is home to thousands of law students seeking exposure to commercial law.

\footnotetext{
${ }^{1}$ A Weinberg and J Heine, Counseling the Startup: How Attorneys Can Add Value to Startup Clients' Businesses, 15 JOURNAL OF BUSINESS AND SECURITIES LAW 39 (2014)

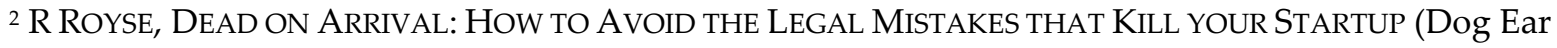
Publishing, 2012)

${ }^{3}$ U Dulleck, P Frijters and R Winter-Ebmer, Reducing Start-up Costs for New Firms: The Double Dividend on the Labor Market, 108:2 SCANDINAVIAN JOURNAL OF ECONOMICS 317 (2006)
} 
Hourly rates for commercial lawyers in London can be upwards of $£ 400$ per hour ${ }^{4}$ and legal aid is unavailable for civil matters. Given the high cost of legal advice, early stage startups typically lack access to the very resources they require in order to protect their future interests until a time when their capacity to secure advice may be more feasible. This paradox is particularly troublesome given that studies have shown that it is often the least well-financed startups which demonstrate the most dedication to their business. ${ }^{5}$ The implication is clear that the inaccessibility of legal advice operates as one of the main barriers to the innovation and self-employment that could otherwise be generated by the startup sector.

While the startup phenomenon itself, including London's "Silicon Roundabout" cluster has received much attention from scholars ${ }^{6}$, as well in the media ${ }^{7}$, there remains surprisingly little research into the legal problems faced by early stage startups, nor, crucially the extent to which it can be serviced by legal clinics based in universities. Better identification of the nature of the legal queries brought by startups to their lawyers could help contribute to the streamlining of basic legal services by legal clinics (as well as law firms), particularly if this identification were to include an

\footnotetext{
${ }^{4}$ Civil Justice Council Costs Committee, Report to the Master of the Rolls: Recommendations on Guideline Hourly Rates for 2014 (May 2014) <https://www.judiciary.gov.uk/publications/master-of-the-rollsdecision-and-committees-report-on-guideline-hourly-rates/>

${ }^{5} \mathrm{H}$ Hvide, J Moen, Lean and Hungry or Fat and Content: Entrepreneurs' Wealth and Start-Up Performance, 56:8 MANAGEMENT SCIENCE 1242 (2010)

${ }^{6}$ e.g. , R Dale and K Zell, Startup Ecosystems: A Look at Entrepreneurship in London and Boulder (15 Oct 2014) <http://www.leedsscholars.com/wp-content/uploads/2014/10/Startup-Research-Paper-FinalDraft.pdf $>$ (accessed August 2015)

${ }^{7}$ e.g. B Thompson, London Tech Hubs Evolve to Challenge Silicon Roundabout, THE FINANCIAL TIMES, 16 June 2015
} 
understanding of the difference between the startups' perceptions of their own legal problems (often based on misinformation) and reality. This could channel legal resources in the form of lawyers' billable hours toward more efficient uses. Most importantly, this information could also facilitate the delivery of legal advice to startups from non-traditional sources, such as pro bono clinics at universities such as the one which forms the basis of this study. A clearer understanding of these issues could help eliminate some of the costs associated with progression from early stage to maturity among startups, freeing up scarce resources to develop their businesses through the acquisition of talent or through market entrance.

With these trends in mind, this article will outline the activities of Start-Ed, the pro bono law clinic for startups operating at City, University of London. In addition to dispensing legal assistance to more than 500 startups since its inception in 2012, the clinic also administered a client survey resulting in a significant quantity of data on the profile of the startups themselves and on the nature of the legal issues for which they sought advice. During this time the clinic also adapted its model of delivery from its original law-firm style format to a more flexible and informal one, an approach which has met with positive responses from users and ensured its longevity as an extra-curricular activity.

\section{OVERVIEW OF THE START-ED CLINICAL EDUCATION PROJECT}

As a legal clinic, Start-Ed was created in response to the demand amongst law firms as employers for their trainees to demonstrate well-developed "commercial 
awareness" combined with the lack of entrepreneurial education ${ }^{8}$ within The City Law School of City, University of London's standard curriculum, including its pro bono initiatives. Recognising the barriers faced by students from low income backgrounds in gaining commercial experience which is sought by legal employers, as well as the dearth of affordable legal advice available to startups alluded to above, we created Start-Ed in January 2012. It is the law school's first and only commercially focused pro bono law clinic. Initially sponsored by an employability grant from the UK Higher Education Academy, the clinic subsequently received grants from the UK government's Intellectual Property Office and the UK Legal Education Foundation. Although there are a now a number of pro bono law clinics which offer legal assistance to startups and small businesses in the UK, Start-Ed was the first clinic in the UK devoted exclusively to startups and remains the largest in terms of the number of clients that it has served. University pro bono clinics targeting startups have a somewhat more established pedigree in the US where law clinics have been embedded in the curricula of law schools for some time. ${ }^{9}$ The relative scarcity of pro bono law clinics for startups in the UK is remarkable given the growth of technology

\footnotetext{
${ }^{8}$ Entrepreneurial education has become more popular in US law schools: J Bell, Validating the Relationship Between Law and Entrepreneurship: Compelling Commentary and Programme Development as Entrepreneurship Becomes an Offering at US Law Schools Around the Country, 4 SMALL BUSINESS INSTITUTE JOURNAL 1(2009)

9 See S Dangel and M Madison, Innovators Esq: Training the Next Generation of Lawyer Social Entrepreneurs, Symposium: Entrepreneurial Lawyering: Solo and Small Firm Training, Law School PostGraduate Incubators and Residency Programs 83:4 UNIVERSITY OF MISSOURI KANSAS CITY LAW REVIEW 967 (2014-15) at 970-971
} 
incubators in the UK over the past ten years, ${ }^{10}$ possibly disclosing a lack of dynamism within British legal education or a diversion of teaching resources to more traditional clinical education projects, such as the Free Representation Unit.

Start-Ed was created in part based on our view that basic legal advice is all that is required for many startups to advance to the next stage and progress into a position to seek funding from venture capitalists. We theorized that such routine assistance can be readily dispensed by legally trained individuals such as students supervised by lawyers at relatively low cost, precluding some of the barriers associated with clinic projects at law schools such as the need for expensive, specialized training for students and multiple visits from clients.

This is why, in addition to its societal function to dispense free legal advice to the startup community, Start-Ed can also be seen as a sector-leading example of the remarkable effectiveness of experiential learning. ${ }^{11}$ Most importantly it is an activity through which law students can gain exposure to real clients and participate in providing legal assistance under the supervision of qualified lawyers. The clinic was designed to target London's vibrant startup ecosystem, regularly identified in the press and by politicians as one of the key engines of the UK's future economic growth. City, University of London is exceptionally well placed to offer a pro bono service to

\footnotetext{
${ }^{10}$ P Miller and K Bound, The Startup Factories: The Rise of Accelerator Programmes to Support New Technology Ventures, NESTA Discussion Paper, June 2011

<https://www.nesta.org.uk/sites/default/files/the_startup_factories_0.pdf>

11 The values and practices of experiential learning have been identified by J ROBERTS, BEYOND

LEARNING BY DOING: THEORETICAL CURRENTS IN EXPERIENTIAL EDUCATION (Routledge, 2012) at 2-5
} 
this particular segment given its proximity to London's Silicon Roundabout, an area with a high density of technology-oriented firms.

The format of the Start-Ed clinic was (and is) as follows: during weekly evening sessions (Tuesdays) undergraduate and graduate law students worked directly with a lawyer who offered commercial legal advice to early stage startups. Law students were enrolled in the Start-Ed clinic on a first come, first serve basis, initially attracting interest from about seventy students across all taught programs (including professional programmes), with twelve attending on each evening in groups of three or four students (three or four lawyers attended each evening). Over its first three years of operation (2012-14) Start-Ed normally attracted between 8-15 clients per weekly session, with less in the early stages because of the clinic's lack of recognition within the startup community at that time. Most of the clients initially discovered the clinic through direct marketing at local startup incubators such as the nearby Google Campus where adverts were posted. Over time the clinic's outreach was done primarily through on-line professional networking websites such as MeetUp as well as word of mouth as our reputation grew. Students were not assessed for their participation in Start-Ed as it was (and remains) an extra-curricular activity. There was always one full time member of staff present who normally acted as a greeter, although there was often two members of staff, with one assisting in the timing of the sessions.

During the sessions, students conducted an initial intake interview with the client, outlining the nature of the service provided and determining the general nature of the 
business and potential legal matters raised. The lawyer would then join the session offering advice / assistance based on his or her assessment of the client's needs, typically with input from the students over a 20-30 minute session with each client. The relatively short time spent with each client captures Start-Ed's unique model of delivering high-level signposting of key legal issues that the startup has already encountered or may do so in the future, often putting the clients in a position to reassess their approach and assess whether they need additional and more comprehensive legal advice from other sources. While clients were welcome to return to subsequent sessions for additional assistance, the service offered by Start-Ed was in no way intended to offer full legal representation nor did we form ongoing relationships with particular startups. This was always made clear to clients who signed a waiver at the beginning. Students completed non-disclosure agreements to ensure the confidentiality of any sensitive commercial information disclosed by clients during the sessions.

This format allowed us to maximize the number of startups we were able to help, giving students wide exposure to the practice of identifying legal issues and, interestingly, giving the clinic a representative overview of the nature of London's startup scene. In other words, we were able to get a sense of the ideas that people were attempting to commercialize and how this process engaged with the practice of commercial law. This experience was intended to foster law students' capacity to approach the clients' needs from an entrepreneurial standpoint, anticipating what commercial problems may exist now or in the future, rather than exclusively focusing 
on legal matters. We observed that clients were often very eager to explain their ideas to a receptive but critical audience willing to offer constructive feedback, an environment which might possibly be unrealistic in the context of a lawyer billing by time. The application of entrepreneurial skills to traditional legal advice is now recognized as a key expectation that clients have of their lawyers ${ }^{12}$ as well as a vital component of modern legal education often requiring more experiential type environments such as law clinics. ${ }^{13}$

The informal setting avoided some of the stress associated with traditional legal advice in an intimidating, office-like environment. Moreover, the interplay between the students and the lawyer/advisor arrangement allowed students to develop their basic client-facing skills at their own pace. It also facilitated the application of the taught knowledge from their classes to actual legal problems. We conducted a number of mandatory training sessions for the student participants prior to the sessions commencing each term. These included instruction on corporate and commercial law and basic intellectual property law. Through its popularity among students and its growing prominence in London's startup scene, by 2013 the clinic had become one of the flagship extra-curricular activities offered by the City Law School. Through a grant from the Legal Education Foundation, the clinic model has now (as of 2016) been expanded to three other law schools in the UK: Liverpool John Moores, Birmingham City University and Manchester Metropolitan University. The clinic is a viable project

\footnotetext{
12 Weinberg and Heine, supra note 1

${ }^{13}$ Dangel and Madison, supra note 9 at 969
} 
in any university that is near to a centre of startup activity as a source of clients, which is now most of the large cities in the UK.

\section{CHALLENGES AND ADAPTATIONS}

The chief problems we experienced during the clinic consisted of the non-attendance or under-attendance of either students, lawyers or clients. A contingency plan was arranged for each of these scenarios as follows. First, with respect to the nonattendance of lawyers (a regularly occurring problem since the lawyers were not paid for their participation and often arrived late or cancelled due to other commitments) the sessions would proceed in an even less formal manner, with clients discussing their business idea with groups of students and then students offering their thoughts, with the clear understanding that this was not genuine legal advice. This necessitated a more emphatic explanation of the difference between legal advice and legal assistance. During sessions without lawyers, clients were also given more time to network with each other before meeting the students, an approach which was met with much success and positive feedback from our clients as well as the students. In sessions without clients, which occurred on a few occasions particularly during poor weather or nearer to Christmas, the sessions were re-structured as informal discussions between students and lawyers with lawyers given the opportunity to talk about their practice and some of the legal issues they commonly face which could be of interest to startups. One of our attending lawyers led an impromptu conversation on intellectual property issues commonly faced by tech-oriented firms. These informal 
sessions were invaluable because they served the purpose of training for students for when they met actual clients. Of course these arrangements also served the useful purpose of allowing students to interact with potential future employers who were able to give them career advice. Despite the fact that the clinic was non-assessed, there were no sessions in which there was non-attendance by all students - we never had less than five students present at each session.

The volume and dedication of students, while laudable, posed one of the key difficulties associated with Start-Ed in its second year when it had become a popular extra-curricular activity at the City Law School. Somewhat of a victim of its own success, clients reported to us that having large groups of students sitting with them could be intimidating. But faced with pressure to include as many students as possible because of the beneficial impact upon student employability, there was little we could do to decrease student numbers, particularly when the number of startups attending was small. We responded to this problem by emphasizing the informality of the process, having sessions on couches rather than around tables and specifically telling our students not to wear formal clothing (in our first year we had urged students to wear business attire when attending the clinic). The setting of the clinic itself (the law student common room) was a much less formal one than that which we used initially (break-out meeting rooms in a library which resembled board rooms). We adopted a more easy-going manner when greeting clients at the door and encouraged everyone to relax during the sessions. This was a very successful approach which appeared to 
be in keeping with the working environments associated with well-known startups like Facebook and Google.

Another problem which we encountered during our first two years was managing the expectations of the clients who had attended as a consequence of our marketing on various social media websites, including notably MeetUp. This website organizes "events" such as lectures or networking parties rather than meetings in the conventional sense as would occur between a lawyer and her client. Consequently many of the clients attending expected that they would passively witness a lecture rather be pressed to explain a business they had started and for which they sought precisely formulated legal queries. Accordingly many of the clients again reported that they felt "put on the spot" and that they were not ready to receive formal legal advice. We dealt with this issue again by reducing the formality of the process and encouraging the clients to network with each other in the waiting area before they met with the students. We would modify the language we used by saying that the clients would "have a chat" with the students and referring to the clients themselves as "startups" or "founders." In this way they did not perceive themselves as clients but rather as individuals attending an event in which they would acquire legal knowledge which would or could help them.

There were ongoing issues about the level of participation by our law students, with some adopting a more passive role and some a more active role. Typically our postgraduate students spoke more often and tended to have more confidence in terms of their legal knowledge (although this confidence was not always well-placed). This 
remains one of the pressing problems with having a non-accessed clinic - it is difficult to make certain that students are actually proactively learning. In one sense this could also be viewed as a strength because it allowed students to get involved at their own pace and within their own comfort zone. We encouraged the lawyers to try to get each student involved and curiously many of the clients wanted to hear what each student had to say, but this was impossible to ensure and could not be monitored. We have considered turning the clinic into an assessed module going forward, however we are concerned that this may interfere with the flexibility engendered by the informal and flexible processes discussed above in response to the particular situation which arises during each session.

As a final problem, as soon as we realized that the clinic was successful and would become a permanent fixture at the City Law School there arose issues of legacy planning. We did not intend from the outset that the clinic would last beyond one or two years and the time commitment involved became considerable as the clinic grew. Despite its popularity, our department committed minimal resources to it such that a regular organizer could not be hired. This problem has been resolved through the dedication of our former student participants in the clinic who have been willing to donate their free time to assisting in the planning and running of the clinic sessions each week. In order to ensure that such individuals are readily available for the next year, we recruit from among our existing student participants, two individuals who are willing to act as organizers for the following year and they are paid by the 
university. We found that this format has the added advantage of introducing new students to former students who can share their experiences.

While applying a flexible approach to our clinic sessions addressed many of our problems, we also recognized the need for our student advisors and lawyers to be able to adequately respond to legal queries, which would require that we were properly prepared given our limited time and resources. We felt that this could be achieved by collecting data on the nature of the legal queries which our clients were bringing to the clinic each week.

\section{CliENT SuRvers}

This section will expand on the client surveys conducted by Start-Ed which, as indicated above, was used as a tool to tailor future advice sessions for the purposes of streamlining the clinic services. It should be noted that a second survey is being conducted among our students which should yield insight into how students enjoyed the experience.

The data used in this study undertaken through the Start-Ed sessions described above was collected from surveys which were undertaken with the clients attending each week. The vast majority of startups attending completed the surveys giving rise to a substantial body of data regarding the nature of the individuals seeking the advice of the clinic as well as, by implication the nature of the startup ecosystem in central London. One survey was completed for each startup attending, even if more than one individual was present on behalf of that business. In total 460 surveys were completed 
over the two year duration of the study. As far as we are aware, our study through the Start-Ed clinic was the first of its kind in the UK and possibly the most comprehensive anywhere in terms of the volume of data collected and in terms of the legal issues that startups encounter. It should be noted that a similar study on the nature of legal queries brought to university pro bono clinics focusing on startups was undertaken at UC Hastings College of the Law during the 2014-15 academic year. ${ }^{14}$

The survey was handed to each of the clients upon arrival and they were informed that it was optional and that they only needed to answer the questions they wished. The full list of survey questions was as follows:

1. Name of start-up/project:

2. Description (1 sentence summary):

3. Website (if applicable):

4. Your Age: $<25 \square \quad 25-35 \square \quad 35-50 \square \quad 50+\square \quad$ Undisclosed $\square$

5. Your Gender: $M \square$ F $\square$

6. Date started:

7. Sector: Social Media/Webdesign $\square \quad$ Games $\square \quad$ Financial tech $\square$ Consumer $\square \quad$ Marketing/Advertising $\square$ Consulting $\square \quad$ Social Enterprise $\square$ Fashion $\square$ Other (please specify)

8. Postcode where majority of work is carried out (business location, office/home; where you travelled from to here):

9. Size of Team (number of people):

10. Looking for Interns? Yes $\square$

No

If yes, please provide contact details (name, phone, email):

11. How did you hear about us: $\quad$ Meet-up Group $\square \quad$ Flyer $\square \quad$ Google Campus $\square$ Word of Mouth $\square$ Other (please specify)

14 A Armitage, E Frondorf, C Williams and R Feldman, Startups and Unmet Legal Needs, UTAH LAW REVIEW [forthcoming] <http://papers.ssrn.com/sol3/papers.cfm?abstract_id=2628900> (9 July 2015) 


\section{SURVEY RESULTS \& ANALYSIS}

Several issues emerged from the data collected during our study which allowed inferences to be drawn regarding the nature of startups in London and, most importantly, the types of legal problems that they face. Our primary findings related to the nature of the legal queries which were most commonly raised by our attendees.

\section{A. Primary Results: Difficulties with company structure still evident}

We found from our data that, despite the extensive support in London from national and local governments in terms of setting up businesses, many of the startups which attended the clinic sessions (53\%) still had difficulty in determining the most appropriate corporate vehicle and in structuring their companies. These are among the most basic forms of legal advice, and were often capable of being addressed to full client satisfaction by students in intake interviews before progressing to the advice session with a lawyer. In the context of multiple business partners, even where attendees appeared able to incorporate a business entity with relative ease, they still had difficulty determining appropriate division of ownership rights and formulating agreements between the respective shareholders. Such team-based startups found general issues relating to shares and options extremely difficult to understand and manage. In other words, the majority of queries coming from attendees at the clinic related to the creation of the business entity itself, not the protection of assets or liability matters regarding its relationship to customers. Confirming the study undertaken by UC Hastings noted above, in numerous instances our lawyers and 
students had to diagnose the nature of the legal issues in question based on the attendees' statements, as the attendees themselves often had difficulty identifying these issues on their own.

Given this trend in the legal advice most commonly sought by our clients at the clinic, it would appear that there may be a greater need for law clinics to provide more complete information to startups about not simply registering a business but also basic information concerning division of ownership rights, corporate structure and decision making and shareholders' agreements as well as option documentation to clarify how startups might reward partners, employees and shareholders in a manner that is less legally complex.

After queries regarding company structure, the most significant area of concern related to vendor contracts and terms and conditions. Approximately $21 \%$ of clients had such queries. This covered a wide range of contractual terms from terms and conditions on websites of recently developed startups to terms and conditions as part of contract negotiations with customers. It was a positive reflection of the startups in attendance that many of the terms and conditions which they required assistance with covered potential engagements with customers. This suggested that many of them already had a product in the market and were actively in discussions or negotiations with potential clients. In contrast, there were very limited queries relating to employment, most likely indicating that few startups were in a financial position to hire support outside of the core team. 
As the third leading issue, approximately $12 \%$ of clients had queries related to intellectual property. This trend indicates that many startups at least perceive that they have developed some kind of novel idea worth protecting, although more often than not our attendees had not actually created rights worthy of legal protection, demonstrating the gulf between our attendees' perception of their situation and the legal realities as identified by our lawyers and students. Some of the intellectual property queries stemmed from the complexity of the patenting system in the UK in particular as it applied to software. Our startups showed more awareness of trademark requirements and a number were familiar with the system through which a trademark can be filed online through the UK government website. ${ }^{15}$ However, the attending startups were less aware of the additional support and guidance that the government provides in the context of classification of trademarks and in responding to queries where there are similar marks. Finally, our startups demonstrated limited awareness of the government's search capabilities to establish whether a trademark had been previously registered - perhaps once of the most fundamental (and important) checks before establishing business names.

\section{B. Secondary Results: The Nature of the Startups Themselves}

As discussed above, one of the objectives of this study was to gather information regarding the nature of the individuals who were starting their own businesses in

\footnotetext{
${ }^{15}$ The Intellectual Property Office: <https://www.gov.uk/government/organisations/intellectualproperty-office>
} 
London as well as the precise location and type of business activity. This could help us target our marketing initiatives as well as improve the delivery of our clinic service. It was also used as the basis for our introducing a less formal atmosphere during the clinic sessions.

First, our study revealed that the 25-35 year old age bracket was by far the most common one to seek legal advice through our clinic. Fifty three percent of the surveyed group fell within this range. The next most prevalent category, falling between the ages of $35-50$ years old made up only $16 \%$ of the total surveyed. ${ }^{16}$ Only $6 \%$ of our clients were over the age of 50 . These results may be attributable to several facts. Perhaps most obviously, this trend may reflect that starting a business based on a novel idea (a startup) is less appealing to older people, many of whom are already established and have secure employment. It may also indicate that older people who are seeking to become self-employed have sufficient resources to hire their own lawyers or that they have extensive life experience or networks such that they do not require basic legal assistance from a pro bono clinic in a law school. It may be equally possible that the format through which we advertised the clinic (primarily on-line as well as posters and flyers in office hubs) was more conducive to attracting younger age groups. The younger age group seemed particularly responsive to our more informal style of discussion on couches rather than around tables.

\footnotetext{
${ }^{16}$ For data on age in which there was more than one individual present for each company, we asked clients to nominate a leading representative for the purposes of the study.
} 
Secondly, our data showed that in terms of the male/female split among clients attending our clinic, there were substantially more men than women $(60 \%$ male to $38 \%$, with $2 \%$ of businesses comprising men and women combined). This fact broadly concurs with trends observed by larger studies conducted in the US. ${ }^{17}$ Encouragingly, the gender gap observed in our study was not as substantial as that found in other British studies which have reported female participation in self-employment to be less than one third that of men. ${ }^{18}$ The difference in these figures may signify that women are more comfortable seeking legal advice than men, or perhaps more likely, that they are more likely to seek free legal advice from clinics situated in universities such as ours than most men. Indeed, a study of the British startup ecosystem found that men are $86 \%$ more likely to be funded than women ${ }^{19}$, suggesting that female founders are more likely to be needful of free assistance than their male counterparts who can pay for their own lawyers. In terms of the type of business focus by gender, our study found that there are substantially more men in FinTech (financial services technology startups) than women (a ratio of 14:3) whereas there were far more women in fashion startups than men (a ratio of 7:2) which may be taken to confirm traditional gender stereotypes. We note that there was a near perfect gender balance among our student

\footnotetext{
${ }_{17}$ V Kuppuswamy and E Mollick, Hubris and Humility: Gender Differences in Serial Founding Rates ssrn.com/abstract=2623746 (26 June 2015)

${ }^{18}$ Labour Force Survey, Office of National Statistics (UK) 2013.

${ }^{19}$ A Guttman, Why Men are 86\% More Likely to be Funded than Women, Forbes Entrepreneurs, (15

September 2015) <http://www.forbes.com/sites/amyguttman/2015/09/15/why-men-are-86-more-likelyto-be-funded-than-women/\#4d860dd22bc7>
} 
participants (as well as our advising lawyers), which occurred accidentally as we did not select students or lawyers on this basis.

Third, we found that only $30 \%$ of our clients were solo entrepreneurs, with the majority of businesses attending comprised of between 2-4 individuals (48\%). Fifteen percent had more than 5 individuals working on the project. The preponderance of teams coming to our clinic was encouraging given that there is evidence to suggest that solo entrepreneurs are less likely to succeed in business than teams. ${ }^{20}$ The relatively high incidence of teams using our service may also reflect the fact that there is some apprehension associated with seeking legal advice, or indeed attending an event with strangers on one's own. People tend to be more confident in groups. If most startups are indeed characterized by teams rather than individuals, it might be worthwhile for university clinics or business/law faculties to establish match-making type programmes in which individuals with certain talents can be paired with those with other abilities in order to create "synergies" which could lead to profitable teambased businesses. Again, group-based clients seemed particularly well-suited to the casual discussion format as well the networking opportunities at the start of each session on which we placed greater emphasis over time.

Fourth, social media startups were the most popular sectors using our clinic, with over $30 \%$ operating in this area. As a representative sample of startup activity in London,

\footnotetext{
${ }^{20}$ D KlONOWSKI, STRATEGiC ENTREPRENEURIAl FinANCE: From VAlue CREATION TO REALIZATION (Routledge, 2015) at 54. Start-Ed did not collect data on the success or lack thereof of the startup in terms of securing funding or any other metric going forward.
} 
our study confirms that the London startup ecosystem is very much characterized by social media startups, despite the city's image as a hub of technology or financial services-oriented entrepreneurialism. This trend may be explained by the fact that costs associated with social media startups are lower. Generally speaking there is no need for investment in equipment or inventory other than a website. Businesses sensitive to such costs would likely be the ones which would need to resort to a free legal advice clinic rather than hire their own lawyers. The popularity of social media startups may also reflect the community which was most responsive to our clinic's marketing, namely individuals who use social networking sites such as Meetup or who have links to universities or law students. To some extent this trend may also be driven by popularity of social media platforms among younger age groups as well as the pervasive presence of the young billionaire archetype in social media startup mythology. It is clear that financial sector startups, which one might more readily expect in London given its status as a global financial hub, face their own set of challenges, including most notably extensive regulation. This may explain why less than $10 \%$ of our attendees were working on projects in this sector. Still, one might expect that FinTech startups would accordingly be the most likely to seek legal advice for compliance purposes. Recent UK government initiatives such as grants for cybersecurity ${ }^{21}$ and compliance assistance may be supporting many FinTech startups,

\footnotetext{
${ }^{21}$ New $£ 5000$ Government Grant for Small Business to Boost Cybersecurity, (16 July 2015) UK Department for Culture, Media and Sport, https://www.gov.uk/government/news/new-5000-government-grantfor-small-businesses-to-boost-cyber-security
} 
thereby making them less likely to seek free legal advice. Furthermore, it is worth noting that very few bio technology firms attended our clinic, which may indicate that either this sector is less vibrant in London than is often thought ${ }^{22}$ or that such firms, which tend to require significant capitalization, are more likely to secure their own funding and once this is obtained will not require free legal advice. Alternatively such firms may embedded in universities where in house legal support is made available to these so-called spinouts.

Finally, it appears from our data that London's Silicon Roundabout cluster of startup activity remains a key hub, despite reported migration of startups to other parts of London. ${ }^{23}$ Most of the clients attending the clinic reported place of business addresses in or near London's so-called Silicon Roundabout (near the Old Street Underground Station) at the boundary between the City of London (effectively the financial district) and the area of Shoreditch. This finding is consistent with a study which revealed that this area is the most popular postcode for new technology businesses in the UK. ${ }^{24}$ Of course, this zone is also the one in which City, University of London (and the clinic itself) is located, leading to another possible and somewhat more banal interpretation that startup owners do not want to travel far for legal advice, even if it is free. The second most popular place of business for attendees was central London (Westminster/Mayfair) capturing the density of that area's population as well as its

\footnotetext{
${ }^{22}$ D Roland, London to Complete "Golden Triangle" of UK BioScience, THE TELEGRAPH (5 April 2014)

${ }^{23}$ Thompson, supra note 7

${ }^{24}$ H Williams, New Study Reveals London's Top Tech Post Codes, Startups, Startups.Co.Uk, 15 September $2015<$ http://startups.co.uk/new-study-reveals-londons-top-tech-postcodes/>
} 
association as another cluster of significant startup activity. Other popular areas of London in which our attendees' place of business was located were Knightsbridge (associated with affluence and retail) and adjacent to Canary Wharf (a second financial district). The clumping of our clients into distinct areas rather than an even spread across the London area suggests that clustering may be a genuine phenomenon for startups. We will continue to target our clinic promotion initiatives as these zones.

\section{CONCLUSIONS: POLICY IMPLICATIONS FOR CLINIC PRACTICE}

Legal advice clinics in law schools are well placed to provide commercial legal assistance to the growing number of self-employed startups and in so doing offer an invaluable experience to law students seeking elusive commercial awareness. For their part, startup founders often find themselves in the invidious position of choosing between short-term and long-term prosperity. Their company's long term health would benefit from a large investment in legal advice upfront, but such expenditures are impossible where there are insufficient resources available at the early stage before the project has been identified as viable. ${ }^{25}$ For law clinics, there is often simply not enough time or sufficiently knowledgeable advisors to provide adequate legal assistance in brief sessions.

A plausible resolution to this dilemma is for clinics to follow Start-Ed's model by identifying the basic legal issues which appear to face most early stage startups and

${ }^{25}$ Armitage, Frondorf, Williams, and Feldman, supra note 15 at 15 
to train students, supervised by qualified lawyers, to administer this high level advice for free. This serves the dual purpose of firstly providing routine but essential legal assistance to low-resourced firms in order for them to proceed to the next stage of their development when more comprehensive legal representation is warranted and affordable and, as a subsidiary benefit, offering experiential entrepreneurial education to law students potentially enabling them to be more employable at modern full service firms. Such environments could also facilitate a future training model for junior and unqualified lawyers to meet the demanding technological and commercial awareness requirements of modern law firms.

Although the value of superficial preliminary legal assistance for early stage businesses has been questioned by commentators, in particular in circumstances where more sophisticated agreements are needed, ${ }^{26}$ our study suggests that this this type of advice, such as that relating to basic matters like company structure, is still very much needed by startups in London. At an early stage this basic information is often the extent of the advice that is actually needed in order to progress to the next level of business development which may include marketing, purchasing equipment or hiring employees. In many respects our findings complement those of studies which have shown that in addition to requiring basic legal advice concerning business structure, startups also benefit from assistance in the identification of potential future risks, such as controlling liability through establishment of effective terms and

\footnotetext{
${ }^{26}$ Ibid at 16
} 
conditions on websites. This is likely because of the high degree of uncertainty and unpredictability under which these organisations operate relative to more established businesses. ${ }^{27}$ On the understanding that the businesses attending our clinic are most likely those with the least resources (otherwise they would hire their own lawyers) the fact that we were able to offer simple advice in an often formulaic manner was an effective use of the clinic's lawyers' as well as the clients' and students' time. This viewpoint can be supported anecdotally by the fact that some of our clients reported that they had contacted specialist lawyers previously without satisfaction and expressed plans to do so again in future, optimistic that they would have better results once equipped with the information gained from the clinic sessions. Commentators agree that poorly-resourced startups are in many respects ill-suited as clients for specialist lawyers billing by the hour, with clients accordingly pressured into rushed communications which fail to capture their actual, often rudimentary concerns. This may be one reason why entrepreneurs are often highly sceptical of the value of the lawyer to their business. ${ }^{28}$ Often all they need is a simple answer to a basic question with some helpful signposting as to potential problems that may arise in the future. University law school clinics seeking to assist the startup sector should focus their resources on providing clear information regarding basic structural matters beyond simply incorporating companies, mindful of the fact that many startups are

\footnotetext{
${ }^{27}$ S Sommer, C Loch and J Dong, Managing Complexity and Unforseeable Uncertainty in Startup Companies, 20:1 ORGANIZATIONAL SCIENCE 118 (2009)

${ }^{28}$ Weinberg and Heine, supra note 1 at 46-47
} 
characterized by groups rather than individuals, which raises a different set of legal issues concerning share and reward structures. This could include more straightforward information about shares, options and company capitalization tables (a spreadsheet showing the ownership breakdown of the company), for instance, perhaps using real life case studies in a more digestible form. It could also include online chat resources where standardized information on these topics can be disseminated on a case by case basis. As poorly-resourced startups tend to be operated by younger people, it makes the most sense to dispense this information online and possibly via professional networking events like Start-Ed itself, which are especially popular in larger urban centres like London and will hopefully be replicated successfully in Liverpool, Manchester and Birmingham following our model. Moreover, targeting clusters of startup activity may be both an effective and efficient strategy for government policies attempting to incentivize entrepreneurialism, as it would appear that startups do tend to be established in identifiable geographic zones and will likely seek services offered in close proximity. If it proves true that legal advice sessions among strangers may be an intimidating setting and in particular that this poses a barrier to females attending such sessions, then it may be worthwhile to offer female-only clinic events through Start-Ed in the future. Perhaps most crucially, clinics must be able to offer informal and flexible sessions which can adapt to the situation which arises on each night in terms of the number and nature of the clients in attendance. 